\title{
Mental models for web objects: Where do users expect to find the most frequent objects in online shops, news portals, and company web pages?
}

\author{
Sandra P. Roth *, Peter Schmutz, Stefan L. Pauwels, Javier A. Bargas-Avila, Klaus Opwis \\ University of Basel, Institute for Psychology, Missionstrasse 60/62, 4055 Basel, Switzerland
}

\section{A R T I C L E I N F O}

\section{Article history:}

Received 17 January 2009

Received in revised form 28 October 2009

Accepted 29 October 2009

Available online 13 November 2009

\section{Keywords:}

Web page design

Expectations

Screen design

Mental models

Location of web objects

Schemata

\begin{abstract}
A B S T R A C T
In interface development, it is crucial to reflect the users' expectations and mental models. By meeting users' expectations, errors can be prevented and the efficiency of the interaction can be enhanced. Applying these guidelines to website development reveals the need to know where users expect to find the most common web objects like the search field, home button or the navigation. In a preliminary online study with 136 participants, the most common web objects were identified for three web page types: online shops, news portals, and company web pages. These objects were used for the main study, which was conducted with 516 participants. In an online application, prototypical websites had to be constructed by the participants. Data analysis showed that Internet users have distinct mental models for different web page types (online shop, news portal, and company web page). Users generally agree about the locations of many, but not all, web objects. These mental models are robust to demographic factors like gender and web expertise. This knowledge could be used to improve the perception and usability of websites.
\end{abstract}

(c) 2009 Elsevier B.V. All rights reserved.

\section{Introduction}

Buildings exist in innumerable variations. Before you read on, imagine a typical house. Now, imagine a typical online shop. What does each of them look like?

Your imaginary house may be on one floor or consist of several stories. A garage may be found beside, in front of or underneath it. The windows may have folding or roll-up shutters. It may have a gable or a flat roof. No matter what kind of building one imagines when thinking of a house, some features are consistent in most peoples' minds: a house consists of walls, a roof, windows, and a door. The imagined online shop will certainly have a logo, probably placed at the top of the page. A shopping cart is presumably also located somewhere distinctive. There are certain objects that you expect to find at an online shop. This is true because people tend to form internal mental models of things with which they interact (Norman, 1983; Rouse and Morris, 1986). The idea that people try to match new input with previously known and formed patterns was discussed in the first third of the 20th century by Bartlett (1932). He coined the term schemata for these representations of semantic knowledge. Around thirty years later, Craik (1967) regarded mental representations as mimics of the physical world. People operate on mental representations, he assumed, to produce

\footnotetext{
* Corresponding author. Tel.: +4161267 3568.

E-mail addresses: sandra.roth@unibas.ch (S.P. Roth), peter.schmutz@unibas.ch (P. Schmutz), javier.bargas@unibas.ch (J.A. Bargas-Avila), klaus.opwis@unibas.ch (K. Opwis).
}

predictions and simulate real-world behavior. Minsky (1975) suggested the concept of frames for knowledge representation. He adopted ideas from schemata theory and linguistics, new developments from semantic networks, and first approaches of "objectoriented programming". He built application models of these frames for object recognition or orientation in the environment (Minsky, 1975). A little later, during the 1980s, the term mental model was introduced to describe knowledge representation in the field of cognitive psychology (Gentner and Stevens, 1983; Johnson-Laird, 1983; May, 1996). The following statement of JohnsonLaird (1983) gives an accurate overview of what can be represented and facilitated by using mental models:

It is now plausible to suppose that mental models play a central and unifying role in representing objects, states of affairs, sequences of events, the way the world is, and the social and psychological actions of daily life. They enable individuals to make inferences and predictions, to understand phenomena, to experience events by proxy; they allow language to be used to create representations comparable to those deriving from direct acquaintance with the world; and they relate words to the world by way of conception and perception (p. 397).

Designing web pages according to users' mental models speeds up orientation and enhances memorability of web object locations (Oulasvirta, 2004) and even influence user interactions on the website (Bargas-Avila et al., 2007). Users' age, web design ability, and gender influence Internet usage and perception thereof (Chevalier and Kicka, 2006; Fox, 2004; Madden, 2006; Hargittai and Shafer, 
2006). This paper explores differences and similarities of distinctive user groups' mental models of web pages. Being aware of these mental models is beneficial for web page design.

\section{Theoretical background}

\subsection{Mental models of web pages and their benefit}

The theoretical constructs "mental model", "conceptual model", "mental representation", "frames", and "schemata" are also discussed widely in the field of human-computer interaction ( $\mathrm{HCI})$ as they are especially interesting because of their practical implications (Ben-Ari and Yeshno, 2006; Farris et al., 2002; Green, 1994; Hsu, 2006; Otter and Johnson, 2000; Payne, 2007). The users' mental models on how a device works may influence their interaction with it and therefore it is important to be aware of these models in order to improve design (Rouse and Morris, 1986). Regarding mental models, Norman (1983) postulates that a number of elements have to be considered: the target system, the conceptual model of the target system, and the user's mental model of the target system. The system being learned or used is the target system. The user's mental model develops naturally while using a system whereas the conceptual model serves as a tool for understanding and teaching a system and is invented, e.g., by teachers, designers, scientists, and engineers (Norman, 1983). Users' mental models usually are neither accurate nor robust, because they are built through interactions with the target system, experiences with similar systems, and are influenced by users' background and expertise. Hence, Norman (1983) states that at best the conceptual model is as similar as possible to the user's mental model because it facilitates comprehension and improves usability of the respective systems. The notion of mental models has therefore gained ground in several guidelines for interface and website design (e.g., Apple Inc., 2007; IBM, 2008; International Standards Organisation, 1998; Koyani, 2006; Mayhew, 1992; Sears and Jacko, 2007; Shneiderman and Plaisant, 2005; Tognazzini, 1992). These design guidelines all mention the need to reflect users' mental models, i.e. to take into account users' expectations. By anticipating users' habits, errors can be prevented and the efficiency of the interaction can be enhanced.

As noted above, mental models evolve naturally by interacting through experience with, and knowledge of a system or interface. Hence, it can be assumed that in the course of time users of the Internet have developed certain expectations, i.e. mental models, of individual web objects or even whole web pages. For example, the login area is expected to consist of two labeled boxes of equal size in close proximity to each other (Spool, 2008). Users expect that the first box is for the login name and the second is for the password. If this expectation is not met, users may have trouble finding the login fields and using the login correctly (Spool, 2008). Meeting users' expectations is crucial not only for direct interaction with web pages but also for remembering them. Positioning navigational regions at expected locations and using specific web objects consistently is very important for enhancing memorability of web pages (Oulasvirta, 2004). Not only the layout and naming of individual web objects, but also their particular locations on a web page seem to have created certain expectations. Several studies show that people expect to find web objects such as search, home button, navigation at specific locations (Bernard, 2001; Oulasvirta et al., 2005). Bernard (2001) let his participants place cards symbolising common web objects on a paper grid representing a typical web page. Results showed a clear pattern indicating that there seems to be a common mental model of typical web pages. In a second study, Bernard (2002) investigated user expectations on the location of web objects on e-commerce web pages. Again, general agreement among the participants on locations emerged. A few years later, Shaik and Lenz (2006) examined whether these expectations had shifted since Bernard's studies and found changes in the expected location of the search field, navigation area, and advertisements. However, Shaik and Lenz (2006) asked for expectations of common web objects located on "basic informational websites". This task was more specific than Bernard's, who used the general term "typical web page within a website". Nevertheless, Shaik and Lenz (2006) suggest that these expectation shifts occurred as technology changed the appearance of the Internet.

Design factors, such as complexity, play a crucial role for interactions in the World Wide Web (see e.g., Tuch et al., 2009). Knowing where users expect web objects to be located may be a step towards understanding these factors. Administering this knowledge and exploring if by applying and/or violating mental models website usability and user satisfaction increase or decrease are the next important steps. The studies of Oulasvirta et al. (2005) and Santa-Maria and Dyson (2008) took this step by actually examining the effect of adapting to or violating visual conventions. In Oulasvirta et al.'s (2005) experiments, the link panels were located either only on the left, only on the right, or split between both sides of the web page. Participants were asked to look for a specific link fixated first on the left-hand side of the web page even if the links were divided on both sides. First saccades were more often directed to the left-hand side and when the link panel was placed on the left, fixations were significantly shorter compared to the divided placement. Additionally, the control group indicated that they would guess the target link to be located on the left-hand side. Besides the increased speed of finding the target, Oulasvirta et al. (2005) also found that people were able to remember specific web objects better if they were placed according to their mental models of web pages. Santa-Maria and Dyson (2008) compared conventional and convention-violating web forums and showed that participants browsing the convention-violated forum performed more page revisits and used the back bottom more often than the users of the conventional web forum. After solving five to six tasks, the performance between conditions leveled out. Participants appeared to learn to orient themselves quite quickly on this uncommonly designed web forum (Santa-Maria and Dyson, 2008). However, the violation of the visual conventions seem to have - at least for the first few visits - a negative influence on orientation and performance.

\subsection{Different user groups}

Varying expectations and mental models can on the one hand be explained by factors like advancement of the Internet. On the other hand, internal factors of users may also influence the development of mental models and expectations. Experience or even expertise in web page design can alter the view of the web. Designers differ in many ways from common web users. Chevalier and Kicka (2006) examined the search strategies of novices, experienced web users, and professional web designers. They concluded that professional web designers had difficulties detaching themselves from their own perspective because of the automated procedures that they had acquired through extensive experience. However, very similar search strategies were found between experienced web users and web designers (Chevalier and Kicka, 2006). These findings illustrate that possibly mental models of web pages differ between normal web users and web designers. Considering this, it is also feasible to assume that besides web design expertise other individual characteristics, like for example age or gender, influence the emergence of mental models. Younger people are more often online than older generations (Fox, 2004; Madden, 2006). Not only the frequency of web use but also web activities 
differ between age groups. Young adults for example use the Internet more for entertainment and to acquire information about recreation activities (Howard et al., 2001). In contrast, Internet users aged from 29 to 59 years browse the web for more serious reasons such as job research and visiting government websites (Fox and Madden, 2005). Differences between women and men in computer and Internet use are widely discussed. Some studies have reported that females are still underrepresented in computer and Internet use (Cooper, 2006; Cooper and Weaver, 2003; Pinkard, 2005). Others, however, state that the gender gap has now closed (Wilson et al., 2003). A recent study by Hargittai and Shafer (2006) found that the actual online abilities do not differ between the sexes but the perception of them does. Women estimate their skills significantly lower than men (Hargittai and Shafer, 2006). No studies are known to the authors that have explored whether mental models of web pages differ between certain user groups.

\subsection{Summary and aim of the study}

Including users' expectations and mental models in the design process of web pages and applications is a common procedure in user centered design. Mental models of the locations of web page objects seem to have evolved in the heads of Internet users. Applying mental models in web page design helps users orient themselves, at least during the first few visits. Internet browsing behavior varies between different user groups (e.g., web expertise levels, age groups, and sexes) and may influence expectations of web pages.

The present study aims to expand the existing research in several new areas: (1) Instead of asking for a typical web page, we asked about expectations for three specific web page types: online shop, a news portal, and a company web page. (2) In Bernard's (2001b) study, web objects had to be placed separately and unrelated to each other. In contrast, our participants were asked to actively construct a web page as a whole. They could position the provided web objects interactively per drag-and-drop at their expected locations. (3) Additionally, the size of the web objects to be placed could be adjusted directly by the participants to increase their freedom in expressing their mental models. (4) The present study was conducted as an online survey and as such took place in the users' natural environment. (5) Finally, demographic data, experience in computer and web usage and web design expertise were assessed to build user groups in order to examine whether mental models differ between subsamples.

\section{Method}

The goal of this study was to explore the expected location of the most important web objects depending on the web page type (i.e. an online shop or a news portal) and examine whether diverse user groups have similar or different mental models. We conducted a preliminary study to explore and define the most important web objects and web page types; this is reported in the next section.

\subsection{Preliminary study to identify the most relevant web page types and web objects}

In a first step the most relevant web page types had to be identified. For this purpose, the 100 most visited web pages of the USA, Switzerland, Germany, and Austria were screened and categorized by the authors (Alexa, 2008). The following categories were extracted: company pages (about 35\%), social networking sites (e.g., Facebook, Myspace, etc. about 30\%), online newspapers and news portals (about $10 \%$, for simplicity from now on called news por- tals), online shops (about 5\%), search engines (about 5\%), and various types (about 15\%). Most social network sites are relatively new and targeted to adolescent users. The screening of these sites showed that their appearance varies strongly, suggesting that the formation of clear standards and expectations may not yet have occurred. Therefore it was decided that this category - even though it was the second largest according to the web page screening would not be included in the study. Hence, (1) Online Shops, (2) News Portals, and (3) Company Web Pages were selected for further examination.

To identify the most relevant web page objects for the specific web page types, the following procedure was used: the start pages were screened and all objects were listed. Only objects on the first layer, the start page, were collected. In a second step, these objects were used in an online survey to ask 136 participants which of the collected web objects they expected to appear on the corresponding web page types. Subsequently, web objects that were chosen by more than $40 \%$ of the participants were included in the study (see Table 1).

The results show that users' expectations about web objects are quite congruent to the website's purpose. Accordingly, in online shops users do not expect an archive or external links. Similarly, users do not think that news portals contain information about the conditions of use or a shopping cart. Finally company web pages do not provide an archive, a shopping cart or an advertisement area. This led to a final list of 17 typical web objects for online shops and news portals, and 15 objects for company web pages.

\subsection{Design of the main study}

The study was conducted using an explorative design. Drawings and sketches have shown to be promising tools to assess people's conceptualizations or mental models (Denham, 1993; Kerr, 1990; Thatcher and Greyling, 1998). At the core of the online study was an application where users were able to construct their prototypical website with just a few clicks. They were provided with the corresponding web page objects identified in the preliminary study. These web objects were to be distributed and resized in a browser frame (see Fig. 1). In randomized order, the participants had to construct three different kinds of web pages: a typical online shop, news portal, and company web page. The core application was programmed using client-side Javascript technology. All web object

Table 1

Web objects on online shop, news portal, and company web page.

\begin{tabular}{llll}
\hline Web object & $\begin{array}{l}\text { Online } \\
\text { shop (\%) }\end{array}$ & $\begin{array}{l}\text { News } \\
\text { portal (\%) }\end{array}$ & $\begin{array}{l}\text { Company } \\
\text { web page (\%) }\end{array}$ \\
\hline About us $^{\text {a }}$ & $\mathbf{7 0 . 9}$ & $\mathbf{5 7 . 3}$ & $\mathbf{9 7 . 4}$ \\
Conditions of use $^{\mathrm{a}}$ & $\mathbf{9 7 . 4}$ & 27.4 & $\mathbf{5 3 . 0}$ \\
Archive $^{\mathrm{a}}$ & 5.1 & $\mathbf{9 6 . 6}$ & 36.8 \\
Shopping cart $^{\text {a }}$ & $\mathbf{9 8 . 3}$ & 15.4 & 11.1 \\
Privacy notice $^{\mathrm{a}}$ & $\mathbf{8 8 . 9}$ & $\mathbf{4 2 . 7}$ & $\mathbf{5 0 . 4}$ \\
FAQ $^{\mathrm{a}}$ & $\mathbf{9 2 . 3}$ & $\mathbf{4 7 . 0}$ & $\mathbf{7 1 . 8}$ \\
Help $^{\mathrm{a}}$ & $\mathbf{9 6 . 6}$ & $\mathbf{6 6 . 7}$ & $\mathbf{6 0 . 7}$ \\
Back to homepage $^{\mathrm{a}}$ & $\mathbf{9 5 . 7}$ & $\mathbf{9 8 . 3}$ & $\mathbf{9 8 . 3}$ \\
Contact $^{\mathrm{a}}$ & $\mathbf{9 2 . 3}$ & $\mathbf{9 1 . 5}$ & $\mathbf{9 9 . 1}$ \\
External links $^{\text {Logo }}$ & 29.9 & $\mathbf{8 3 . 8}$ & $\mathbf{6 1 . 5}$ \\
Main area & $\mathbf{9 1 . 5}$ & $\mathbf{9 3 . 2}$ & $\mathbf{9 8 . 3}$ \\
Navigation area & $\mathbf{9 3 . 2}$ & $\mathbf{9 6 . 6}$ & $\mathbf{9 8 . 3}$ \\
Newsletter (link) & $\mathbf{9 6 . 6}$ & $\mathbf{9 8 . 3}$ & $\mathbf{9 5 . 7}$ \\
Search field & $\mathbf{6 7 . 5}$ & $\mathbf{6 6 . 7}$ & $\mathbf{4 4 . 4}$ \\
Sign in/login field & $\mathbf{9 4 . 0}$ & $\mathbf{9 8 . 3}$ & $\mathbf{7 0 . 1}$ \\
To the top (link) & $\mathbf{9 0 . 6}$ & $\mathbf{5 4 . 7}$ & 20.5 \\
Advertisement area & $\mathbf{5 1 . 3}$ & $\mathbf{6 9 . 2}$ & $\mathbf{4 1 . 0}$ \\
\hline
\end{tabular}

Note. Bold numbers, web object was selected for the main study.

a Values represent link \% of people who expected this object on the respective web page type. 

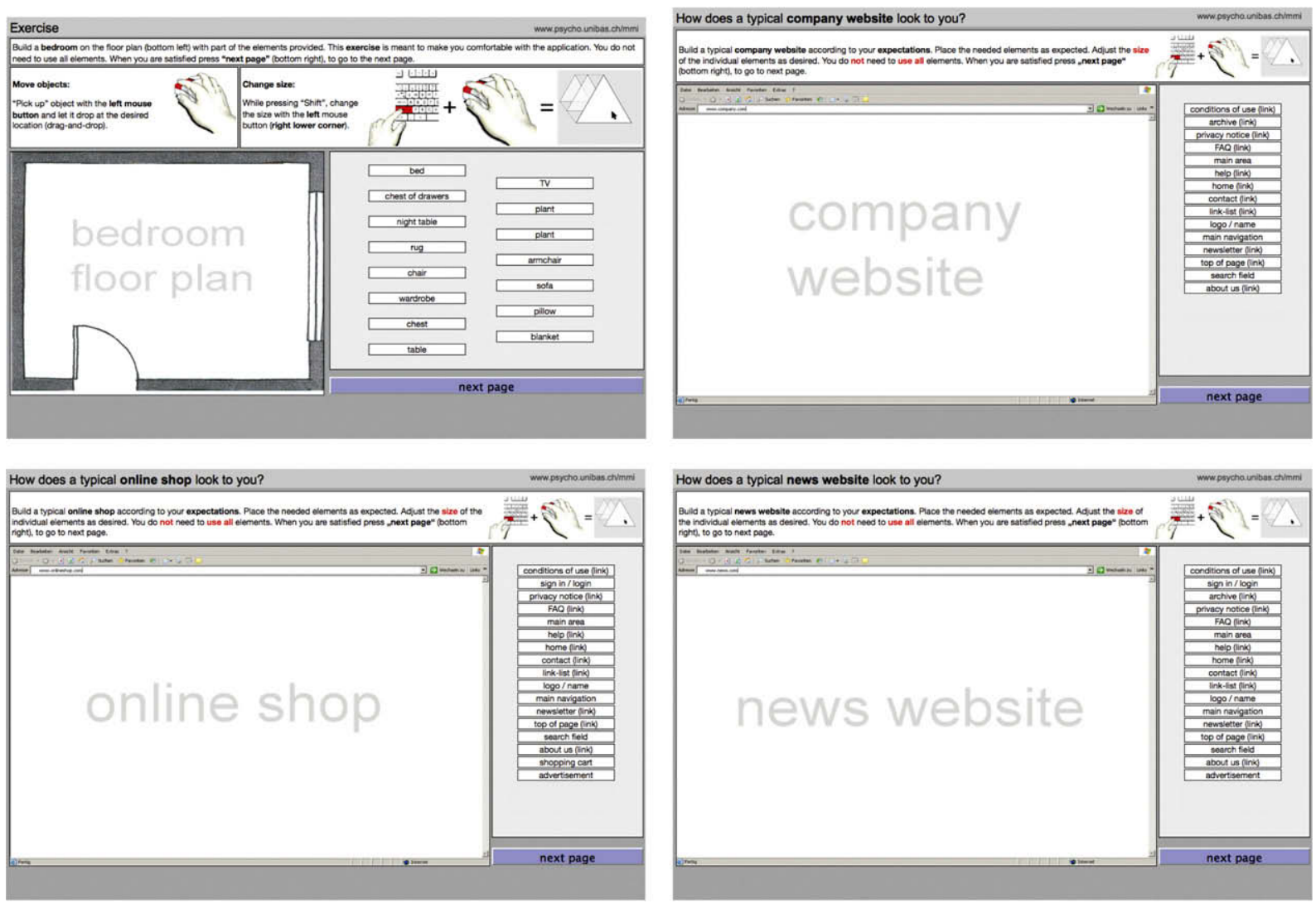

Fig. 1. Screenshots of the online study.

fields were made draggable and resizable using dragdrop.js (Zorn, 2007). Tooltips with detailed information about the respective web object were generated using tooltip.js (Weiss, 2006). Web object positions and sizes were calculated with client-side Javascript technology and transmitted to the database as soon as the participant pressed the "next" button.

\subsubsection{Recruiting and participants}

The link to the study was posted on a university website, several other university web pages, and a variety of bulletin boards. In addition, the Psychology Departments's recruitment database was used to spread the link.

A total of 516 participants (334 women, 179 men, 3 did not indicate their gender) completed the online survey. Of these 78.3\% conducted the study in German, and 21.7\% in English. The mean age was 28.2 years $(S D=9.1)$, ranging from 13 to 67 years.

In all, 1384 people started the survey. Two hundred and ninetynine aborted the study after the language selection. Another 499 quit after the demographic questionnaire. Thirteen participants dropped out during the final questions. Fifteen lurkers were identified (they clicked through the whole study without filling in any information). Ten people completed the study but did not provide the required information. Due to technical problems (the server was down for several minutes), 32 participants were not able to finish the study. No direct payment was offered to the participants; instead, three mp3 players were raffled as an incentive.

\subsubsection{Procedure}

The survey consisted of three parts: (1) the instructions, including a demographic questionnaire and short exercise for learning the handling of the application, (2) the core application of the study, where people could construct their websites, and (3) the final questions section (see Fig. 2). On the first page, participants chose their language (German or English). The welcome page followed, including information about the study. Next, demographic questions (e.g., age, gender) were asked. On the following page participants had the chance to practice handling the application: they were provided with a schematic overview of a room and were asked to place different bedroom items into it. Accordingly, they had the chance to use the drag and drop placement and resizing functions. Then the main part of the study followed. The participants had to create three typical web pages; an online shop, company web page, and news portal. The instructions were: "Build a typical online shop/company web page/news portal web page according to your expectations". The order of the aforementioned types of web pages was randomized to control for sequence effects. Subsequently, participants answered the final questions, assessing computer and Internet knowledge. Afterwards, they had the chance to leave their email address and could indicate if they were interested in participating in the raffle, receiving information about the study results, and/or being contacted to participate in a possible follow-up study. Additionally, a feedback form was provided.

\subsection{Core application: placing of web objects}

Instructions to the task and an explanation of the application's handling were placed at the top of the screen illustrated with pictures to increase understanding. On the left-hand side, a screenshot of a browser window was displayed. The labeled web objects were arranged in a row from top to bottom on the righthand side of the screen. They were all sized the same $(150 \times 18$ pixel). Using the "drag and drop" technique, participants were able to place the web objects in the main area (see Fig. 1). The instructions also stated that participants could decide which web 


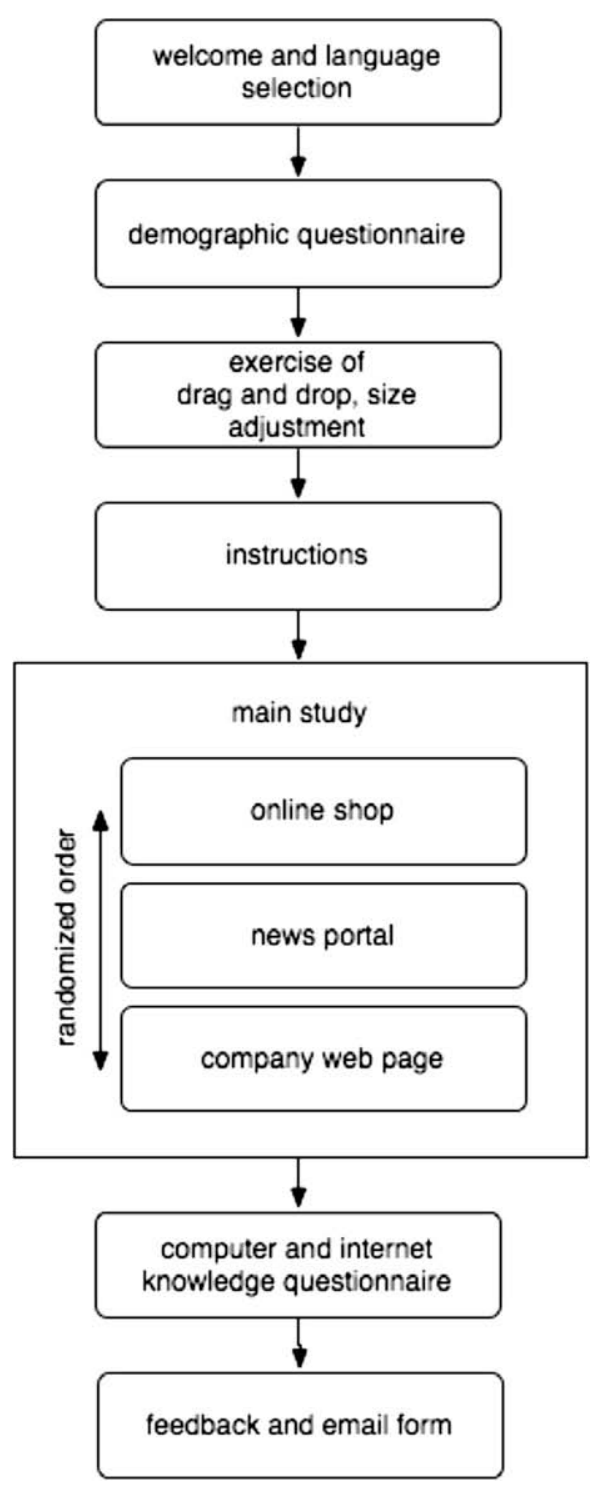

Fig. 2. Schematic illustration of the experimental procedure.

objects to place and which to leave on the selection bar. Also, the web objects could be shifted around as often as desired. People were asked to resize the web objects according to their expectations. By pressing "shift" and pulling the right bottom corner, every web object could be enlarged or made smaller, again as often as necessary. When they were satisfied with their web page, participants could continue and data about position, size, and time were sent to the database server.

\subsection{Data reduction}

Pixel based raw data were reduced into a $12 \times 8$ grid. If at least $50 \%$ of the web object covered a cell, it was counted as a "hit". The higher the number of hits, the darker the color of the cells (see Figs. $3-5)$. The percentages are calculated from the number of placed objects (see Table 3), e.g., 30-34\% means between 30\% and 34\% of the people who placed the object chose this location. Cells were not marked if covered by less than $5 \%$ of the participants. The respective values and coloring of cells were chosen to facilitate a direct comparison to the results of Bernard's studies (Bernard, 2001, 2002).

\subsection{User groups}

Subsamples for gender, and web design expertise were built from the total sample. It was not feasible to create a subsample for web experience because the rating of Internet knowledge and frequency of the total sample was very homogeneous (see Table 2). Similarly, building subsamples of different age groups was impracticable as only a minority of participants were older than 40 years ( $n=57,11 \%$ of the total sample). The gender subsamples consisted of 334 women and 179 men (3 participants did not indicate their gender and were excluded for all analyses of the gender subsamples). For the subsample web design expertise, only the two marginal groups were taken into account. Participants indicating of having no experience in web design were assigned as being "laypeople" whereas participants rating themselves experts in web design were designated as "experts".

\section{Results}

The data were analyzed using SPSS 17. An alpha level of .05 was used for all statistical tests. Non-parametric tests were used for all statistical analyses because normal distribution of the data and homogeneity of variances were not fulfilled. Differing sample sizes within the statistical values are due to individual missing data points.

The mental models of every web object location was compared between the samples of the user groups. To this end, the relative frequencies of all 98 cells $(12 \times 8$ grid $)$ for each web object and web page type were correlated (Spearman's $r_{s}$ ) resulting in 49 correlations per comparison. Considering the large number of cells (observations), it can be expected that most correlations turn out to be statistically significant. In this case, it is reasonable to use the effect sizes to interpret the results. According to Cohen (1988), correlation coefficients can be transformed directly to effect sizes: small effect size, $r>0.1$; medium, $r>0.3$; large, $r>0.5$.

\subsection{Overall results}

Due to the strong similarities between all subsamples, described in more detail below (see 4.2 ), the overall analysis is performed across the total sample.

\subsubsection{Computer/Internet knowledge and usage}

Participants rated their ability to handle a computer, the Internet, and online shopping fairly high. They use computers and the Internet almost daily for business as well as private reasons. On average they read news online and visit company websites between one and three times a week. Most participants do online shopping ranging from at least several times a year to three times a month. An descriptive overview of the results is provided in Table 2 .

\subsubsection{Expected location of web objects: overall analysis}

An overview of the number of placements in percent and sizes in pixel of each web object for the three web page types can be found in Table 3 . Each object was placed by at least $47 \%$ of the participants. In the online shop category, the "external links", "to the top" link, and "newsletter" link were placed by fewer than $60 \%$ of participants. The web objects "main area", "search field", "sign in/login field", "logo", and "shopping cart" were chosen by almost all participants (at least 89\%). A very similar pattern was observed in the news portal category: "external links" and "to the top" link were placed between 57 and 59\% of participants. Again, the web objects "main area", "search field", "sign in/login field" and "logo" were placed by at least $86 \%$. In the company page category, slight variations emerged: the "to the top" link and the "archive" link 
general web objects
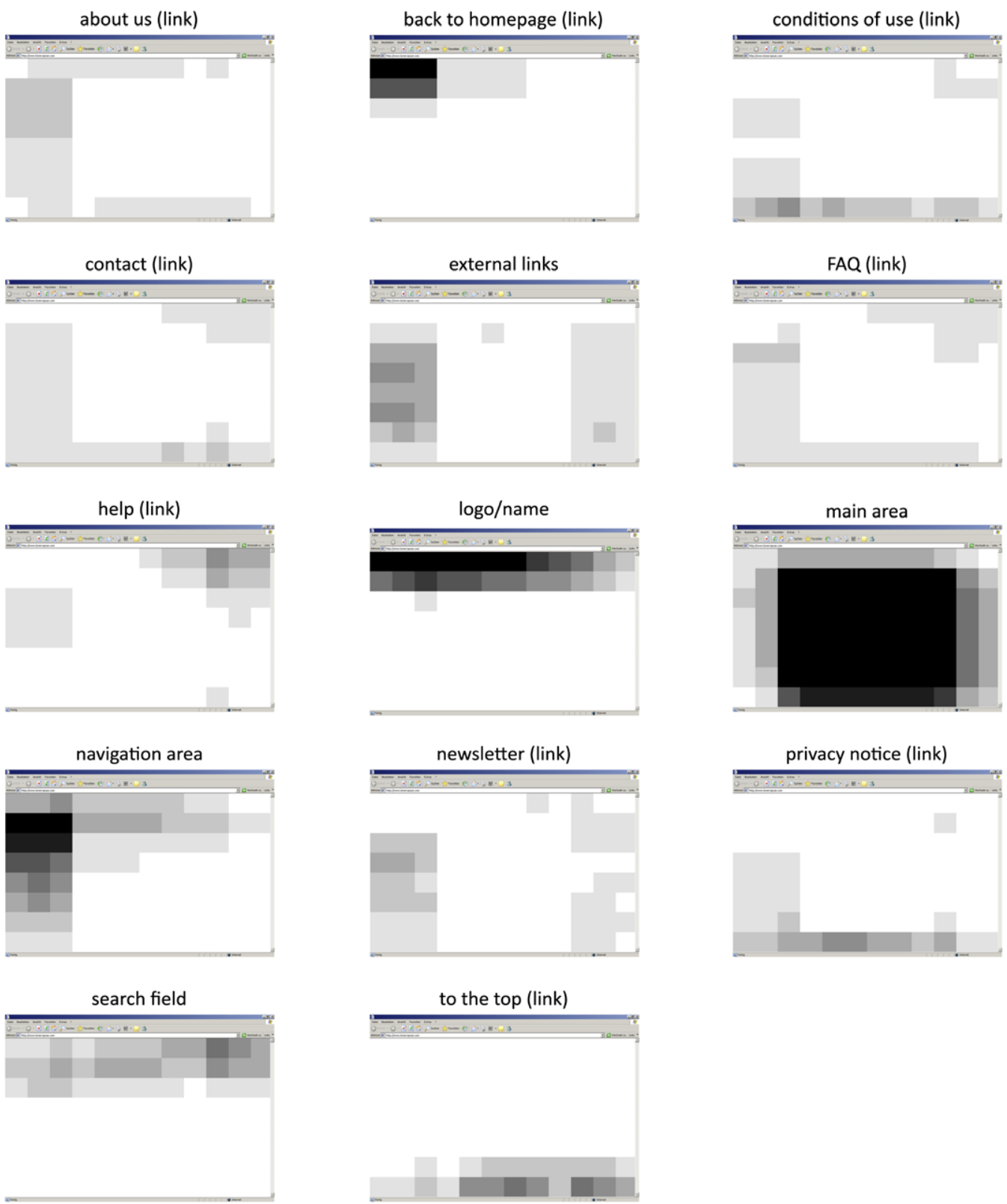

website specific web objects
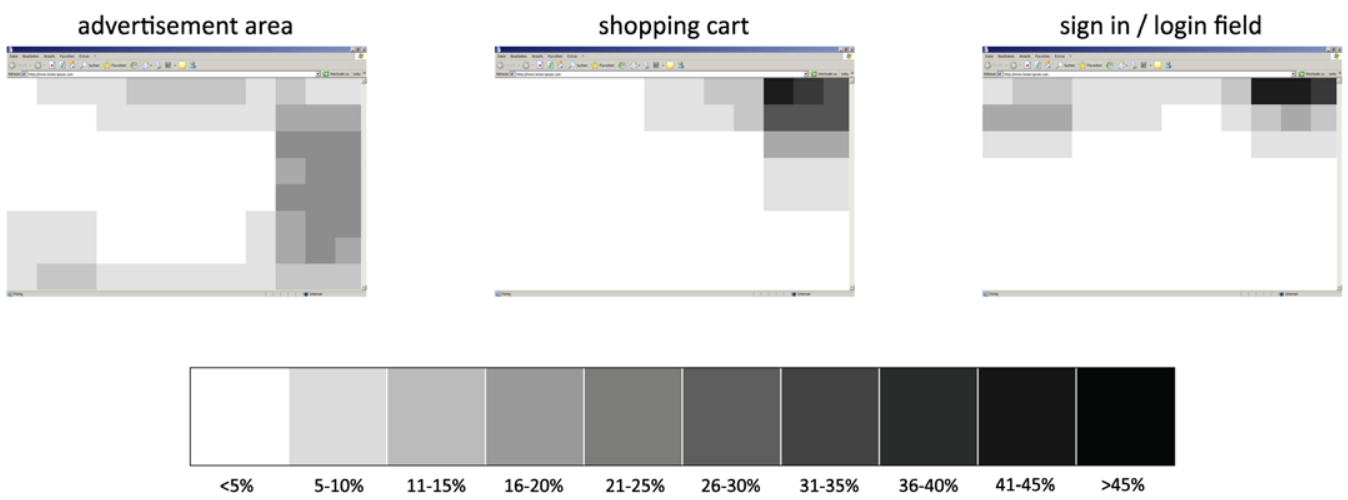

Fig. 3. Percentage of placed web objects on online shop web pages. 
general web objects
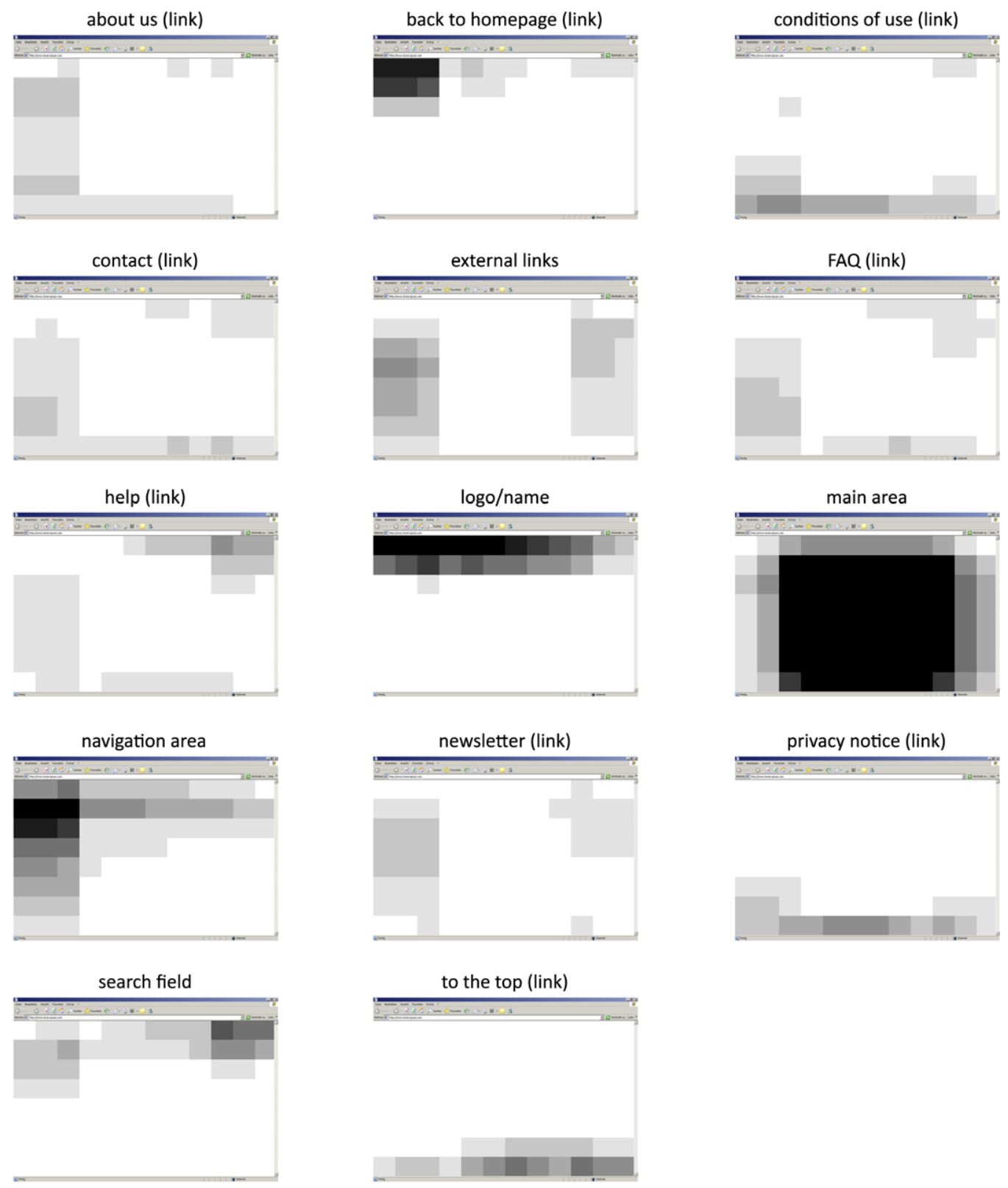

website specific web objects
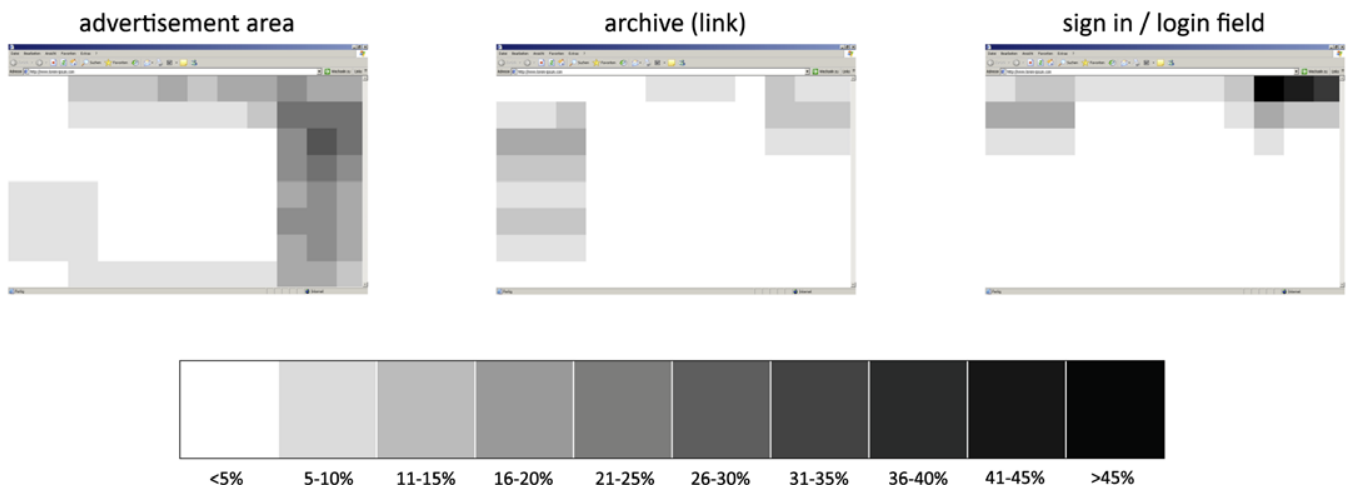

Fig. 4. Percentage of placed web objects on news portal web pages. 
general web objects
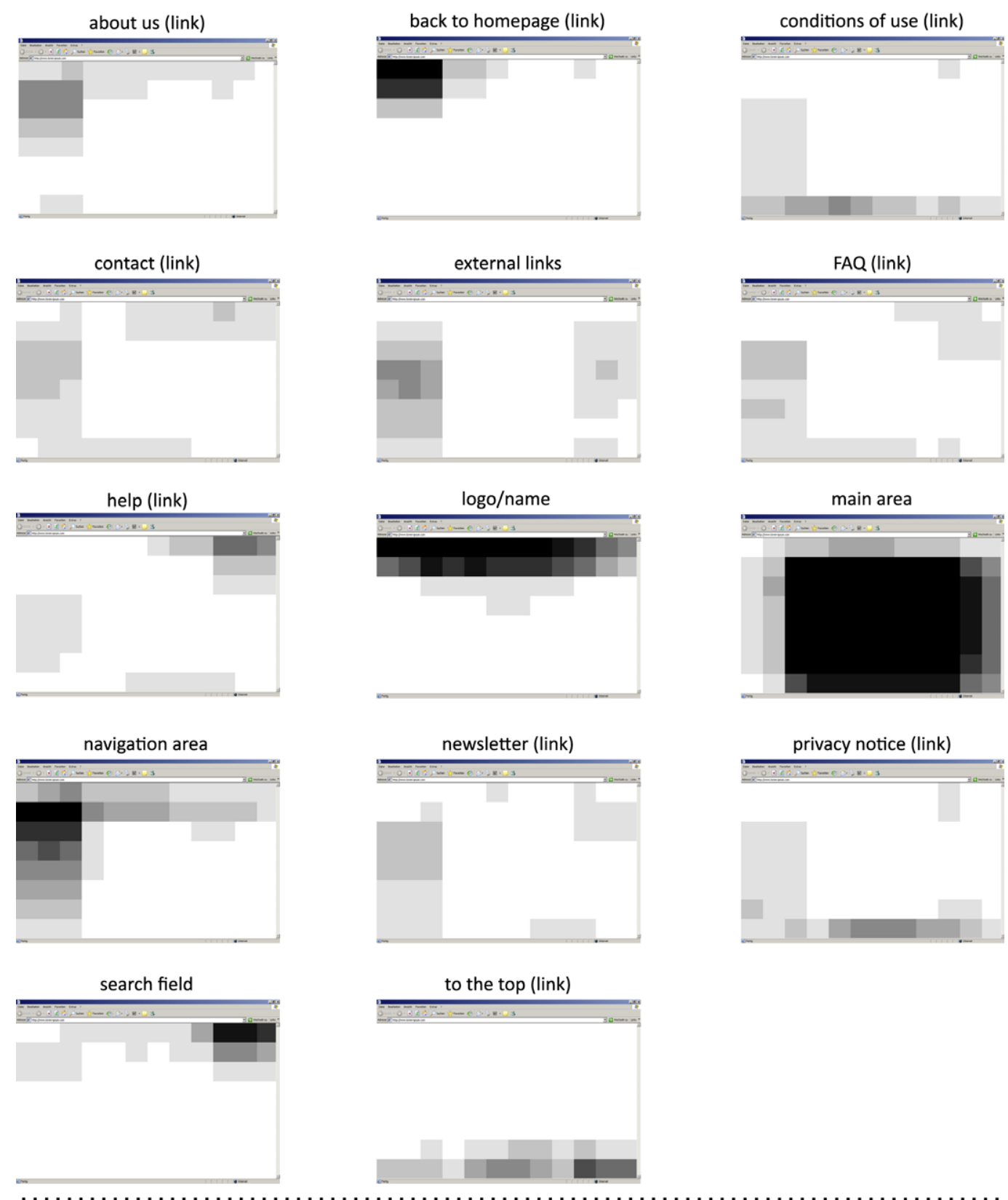

website specific web objects
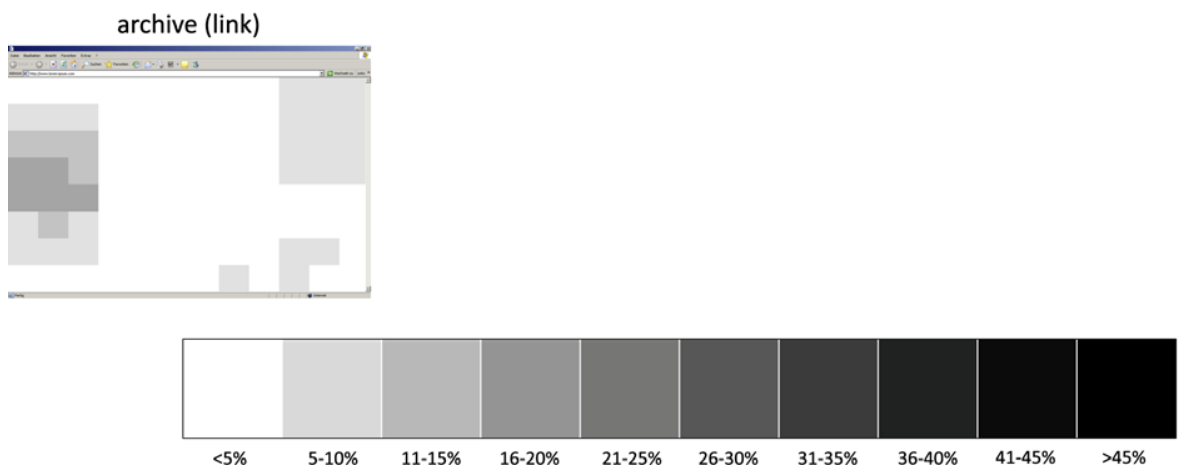

Fig. 5. Percentage of placed web objects on company web pages. 
Table 2

Self-rated abilities and frequency of usage.

\begin{tabular}{|c|c|c|c|c|c|c|c|c|c|c|}
\hline & \multicolumn{2}{|c|}{$\begin{array}{l}\text { Total sample } \\
n=516\end{array}$} & \multicolumn{2}{|c|}{$\begin{array}{l}\text { Women } \\
n=334^{\mathrm{c}}\end{array}$} & \multicolumn{2}{|c|}{$\begin{array}{l}\text { Men } \\
n=179^{c}\end{array}$} & \multicolumn{2}{|c|}{$\begin{array}{l}\text { Web design experts } \\
n=28\end{array}$} & \multicolumn{2}{|c|}{$\begin{array}{l}\text { Web design laypeople } \\
n=169\end{array}$} \\
\hline & $M$ & $S D$ & $M$ & $S D$ & $M$ & $S D$ & $M$ & $S D$ & $M$ & $S D$ \\
\hline \multicolumn{11}{|l|}{ Rate your ability $^{\mathrm{a}}$} \\
\hline In using computers & 4.50 & 1.07 & 4.24 & 1.03 & 4.97 & 0.97 & 5.93 & 0.26 & 3.79 & 1.00 \\
\hline In using the Internet & 4.73 & 0.96 & 4.54 & 0.96 & 5.08 & 0.85 & 5.89 & 0.32 & 4.17 & 0.93 \\
\hline Of online shopping & 4.11 & 1.35 & 3.95 & 1.40 & 4.41 & 1.22 & 5.50 & 0.64 & 3.46 & 1.34 \\
\hline Of designing websites & 2.53 & 1.54 & 2.10 & 1.28 & 3.34 & 1.64 & 6.00 & 0.00 & 1.00 & 0.00 \\
\hline \multicolumn{11}{|l|}{ Frequency of usage ${ }^{\mathrm{b}}$} \\
\hline Internet usage for private reasons & 5.66 & 0.71 & 5.62 & 0.75 & 5.76 & 0.62 & 5.81 & 0.48 & 5.59 & 0.83 \\
\hline Internet usage for business reasons & 4.88 & 1.34 & 4.81 & 1.33 & 5.01 & 1.36 & 5.26 & 1.23 & 4.73 & 1.40 \\
\hline Computer usage for private reasons & 5.71 & 0.66 & 5.66 & 0.71 & 5.81 & 0.55 & 5.87 & 0.45 & 5.69 & 0.69 \\
\hline Computer usage for business reasons & 5.13 & 1.29 & 5.04 & 1.31 & 5.28 & 1.25 & 5.54 & 1.14 & 5.01 & 1.41 \\
\hline Reading online news & 4.02 & 1.74 & 3.75 & 1.77 & 4.52 & 1.58 & 4.26 & 1.53 & 3.65 & 1.76 \\
\hline Online shopping & 2.98 & 1.14 & 2.89 & 1.14 & 3.15 & 1.12 & 3.33 & 0.96 & 2.56 & 1.13 \\
\hline Visiting company web pages & 4.02 & 1.31 & 3.80 & 1.32 & 4.44 & 1.17 & 4.81 & 1.08 & 3.56 & 1.28 \\
\hline
\end{tabular}

Note. 3, 1-4 days a month; 4, 1-3 days a week; 5, 4-6 days a week; 6, daily.

a 1 , no knowledge/experience to 6 , expert.

b 1 , never; 2 , several times a year.

c Three participants did not indicate their gender.

Table 3

Web object properties for all three web page types: number of placements and size.

\begin{tabular}{|c|c|c|c|c|c|c|c|c|c|}
\hline \multirow[b]{2}{*}{ Web object } & \multicolumn{3}{|l|}{ Online shop } & \multicolumn{3}{|l|}{ News portal } & \multicolumn{3}{|c|}{ Company web page } \\
\hline & Placements $^{\mathrm{a}}(\%)$ & Mean width ${ }^{b}$ & Mean height ${ }^{\mathrm{b}}$ & Placements $^{\mathrm{a}}(\%)$ & Mean width ${ }^{\mathrm{b}}$ & Mean height ${ }^{b}$ & Placements $^{\mathrm{a}}(\%)$ & Mean width ${ }^{\mathrm{b}}$ & Mean height ${ }^{\mathrm{b}}$ \\
\hline About us ${ }^{\mathrm{c}}$ & 75 & 140 & 21 & 71 & 142 & 20 & 91 & 144 & 23 \\
\hline Advertisement area & 65 & 183 & 82 & 66 & 192 & 87 & - & - & - \\
\hline Archive $^{c}$ & - & - & - & 82 & 144 & 22 & 59 & 145 & 20 \\
\hline Back to homepage $^{c}$ & 81 & 149 & 24 & 83 & 146 & 23 & 88 & 149 & 24 \\
\hline Conditions of use $\mathrm{e}^{\mathrm{c}}$ & 83 & 139 & 19 & 63 & 142 & 19 & 75 & 142 & 20 \\
\hline Contact $^{\mathrm{c}}$ & 88 & 141 & 20 & 82 & 143 & 19 & 93 & 143 & 23 \\
\hline External links & 47 & 148 & 49 & 60 & 147 & 46 & 62 & 148 & 45 \\
\hline $\mathrm{FAQ}^{\mathrm{C}}$ & 79 & 140 & 19 & 62 & 140 & 19 & 74 & 142 & 20 \\
\hline Help $^{c}$ & 80 & 138 & 20 & 72 & 139 & 19 & 71 & 138 & 20 \\
\hline Logo/name & 93 & 293 & 47 & 93 & 290 & 46 & 96 & 336 & 55 \\
\hline Main area & 90 & 392 & 235 & 90 & 393 & 249 & 91 & 398 & 230 \\
\hline Navigation area & 74 & 216 & 93 & 75 & 230 & 91 & 74 & 218 & 95 \\
\hline Newsletter ${ }^{c}$ & 56 & 141 & 21 & 66 & 145 & 20 & 70 & 144 & 21 \\
\hline Privacy notice $^{c}$ & 76 & 142 & 20 & 61 & 143 & 20 & 64 & 145 & 20 \\
\hline Search field & 91 & 168 & 24 & 92 & 156 & 24 & 86 & 149 & 22 \\
\hline Shopping cart & 94 & 146 & 41 & - & - & - & - & - & - \\
\hline Sign in/login field & 94 & 149 & 25 & 86 & 147 & 23 & - & - & - \\
\hline To the top ${ }^{c}$ & 54 & 146 & 21 & 57 & 148 & 21 & 55 & 148 & 21 \\
\hline
\end{tabular}

a Percent of all participants: $N=516$.

b In pixel.

c link.

were placed by fewer than $60 \%$ of participants. And in addition to the "main area" and "logo", the "about us" and "contact" links were placed by over $90 \%$ of participants. The sizes of the web objects were similar across the three web page types. The "main area" is the largest object in both width and height. Its location is always expected to be at the center of the page. The logo is expected as an elongated rectangle extending across almost the whole width of the page, in all web page categories. All links are expected to be of similar width and height, irrespective of web page category.

Most web objects were arranged at very similar locations across website categories (see Figs. 3-5). More precisely, the "search field" was consistently placed in the upper right corner. In the online shop category, this area was also used for the "shopping cart"; here, it can be observed that the "search field" was placed more diffusely, centered across the upper half of the page. In the online shop and news portal categories, there is a marked expectation that the "sign in/login" field will be positioned in the top-right corner of the web page. In these categories, the "back to homepage" link was placed in the top-left corner at about the same location as the "logo", which stretched further across the top width. The "navigation area" was most distinctly placed across the left-hand side of the web page; however, more diffusely but still quite apparent, it extends also across the top half of the web page. In the online shops and news portal categories, the "advertisement area" was mostly expected on the right-hand side and across the top width of the web page. The "conditions of use", "privacy notice", and "to the top" links were placed across the bottom width of the web pages. The links "about us", "contact", "FAQ", and "help" share roughly the same area of the web page; that is to say, part of the left-hand side, bottom width and top-right corner. Similar expected locations were apparent for the "external links", "newsletter", and "archive" links (where applicable), namely across the left- and right-hand sides of the web page.

However, not only the locations of the different web objects matched across web page categories, but also the grade of congruency or diffusivity, respectively, were similar for almost all web objects. Especially consistently placed across all types were the "back to homepage" link, "logo", "main area", and "navigation area". The 
"login/sign in" in the news portal and online shop categories, the "shopping cart" in the online shop and the "search field" in the company categories were all placed with similar congruency. The remaining general web objects were placed rather diffusely but still with similar patterns across website categories.

\subsubsection{Consolidated model for the three website types}

To help website developers in the placement of web objects, a consolidated model for each web page type should be created. Most locations and sizes of web objects described in Section 4.1.2 are not overlapping and can be easily put together. There are some cases, where a mix-up can be seen. This is especially the case for the "login/sign in" and the "search field" (news portal) and the "login/sign in", "search field" and "shopping cart" for the online shop. In these cases the authors decided to choose the most obvious compromise. Figs. 6-8 show an approximation of consolidated mental models for all website types. Many of the web objects ("logo", "back to homepage", "help", "conditions of use", "privacy notice", "advertisement", and "to the top") in these consolidated models are placed at the same locations across the three web page types. The most salient difference is the search field, which for online shops is placed in the upper part of the web page above the main area almost across the whole width, whereas it can be found in the upper right corner for news portals and company web pages. Another difference is the web object "external links" which is placed at the bottom left for online shops and company web pages

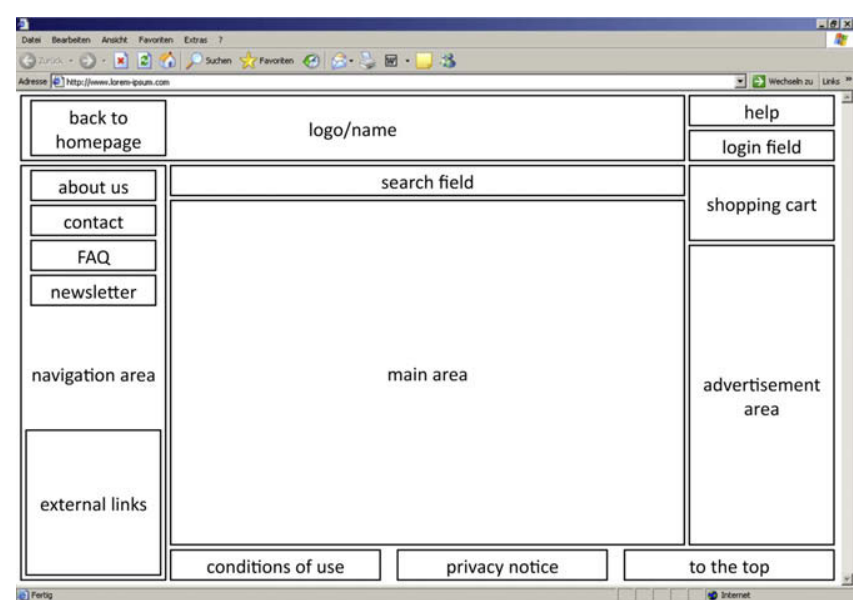

Fig. 6. Consolidated model for online shop web pages.

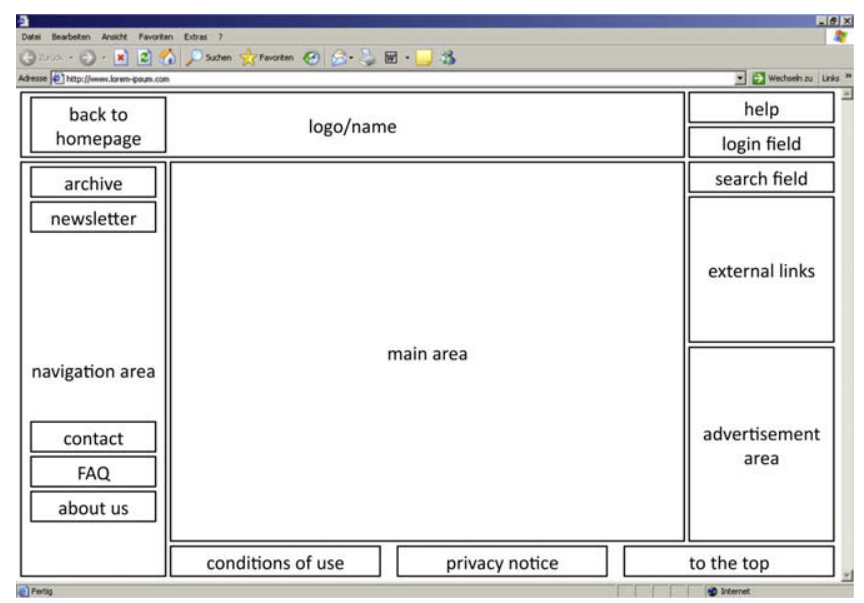

Fig. 7. Consolidated model for news portals.

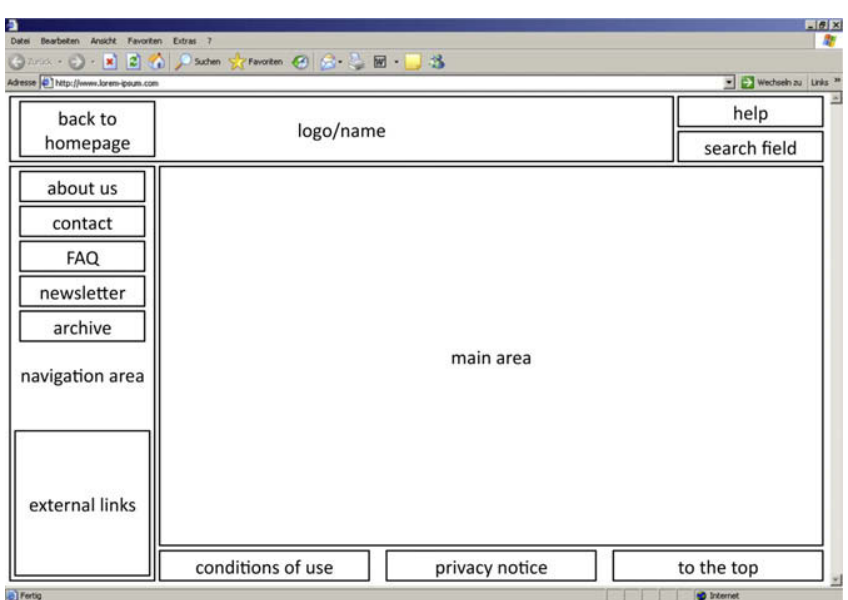

Fig. 8. Consolidated model for company web pages.

but at the right upper part for news portals. The web objects "about us", "contact", "FAQ", "newsletter", and "archive" are located similarly for online shop and company web pages at the upper left side. For news portals, they also are on the left side but appear in a different order.

\subsection{Subsample results}

\subsubsection{Gender}

Self-ratings of computer and Internet knowledge and frequency revealed significant differences between the sexes. Male participants rated their abilities concerning online shopping $(U(333,179)=$ 24203.5, $p<.001)$, using computers $(U(334,179)=18302, p<.001)$, the Internet $(U(334,179)=20627.5, p<.001)$, and their web $f$ expertise $(U(334,178)=16646, p<.001)$ significantly higher than their female counterparts. Men also indicated a significantly higher frequency of Internet and computer usage (Internet private: $U(327,174)=25485.5, p=.009$; Internet business: $U(318,173)=$ $24234, p=.021$; computer private: $U(317,166)=23446.5, p=.005$; computer business: $U(311,165)=22147.5, p=.007)$, reading online news $(U(334,179)=22058, p=.001)$, online shopping $(U(334$, $179)=25737, p=.019)$, visiting company web pages $(U(334,179)$ $=21124, p=.001)$. The means and standard deviations are presented in Table 2.

The expectation of web object location was very similar between men and women. Each of the 49 correlations turned out to be significant $(p<.01)$ and showed large effect sizes (lowest: $r_{s}(96)=0.630$; highest: $r_{s}(96)=0.994 ; M_{r}=0.833 ; S D_{r}(96)=0.083$ ), indicating no differences between gender concerning mental models of web object locations.

\subsubsection{Web design expertise}

Web design experts rated themselves significantly higher in all scores of abilities (using computers: $U(169,28)=174, p<.001$; using the Internet: $U(169,28)=223.5 ; p<.001$; online shopping: $U(168,28)=415, p<.001)$. Web design experts used the Internet and computer more often for business reasons than laypeople (Internet business: $U(162,27)=1612, p=.022$; computer business: $U(159,24)=1387, p=.018)$. Experts also reported higher frequencies of online shopping $(U(168,27)=1375.5, p=.001)$ and visiting company pages $(U(165,27)=1033.5, p<.001)$. However, the groups did not differ either with regard to concerning private computer and Internet use or the frequency of reading online news. Means and standard deviations are shown in Table 2.

Expectations of web object location were also very similar between web design experts and laypeople. All but three correlations 
were significant. The mean of the correlation coefficients was $M_{r}=0.519 \quad\left(S D_{r}(96)=0.205\right)$. The effect sizes ranged from $r_{\mathrm{s}}(96)=0.123$ to $r_{s}(96)=0.979$. The web objects "external links" $\left(r_{s}(96)=0.123, p=.234\right)$, and "newsletter" link $\left(r_{s}(96)=0.169\right.$, $p=.099)$ of the company web page and the "contact" link $\left(r_{s}(96)=0.144, p=.163\right)$ of the online shop did not correspond significantly between groups. In Fig. 9, placements of these objects are presented for web design experts and laypeople. The web design laypeople expected the "external links" and "newsletter" link to be on the left-hand side of the page whereas experts expected them more on the right-hand side. The "contact" link on online shops was expected by the experts mostly around the right top corner; the laypeople on the other hand expected to find it on the left and bottom of the page. Of the remaining correlations, 23 had large, 21 medium, and 2 small effect sizes. To illustrate how correlation coefficients are related to the actual placements of the objects, three examples, one of small, one of medium, and one of large effect size for experts and laypeople are displayed in Fig. 10.

\section{Discussion}

This study explored whether Internet users have distinct mental models for different web page types (online shops, news portals, and company web pages). Participants were analyzed regarding gender and web design expertise to compare their expectations

web design experts

web design laymen

external links on company web pages

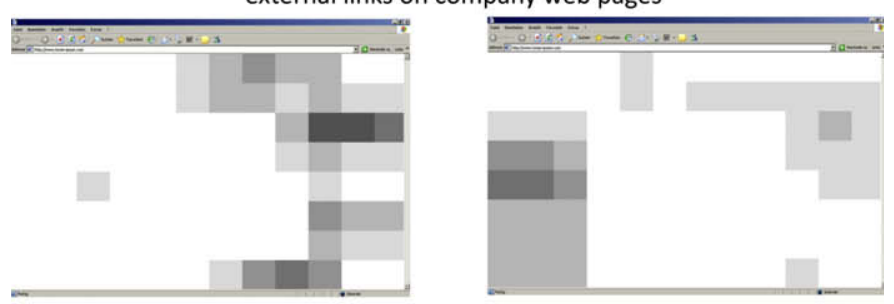

newsletter (link) on company web pages
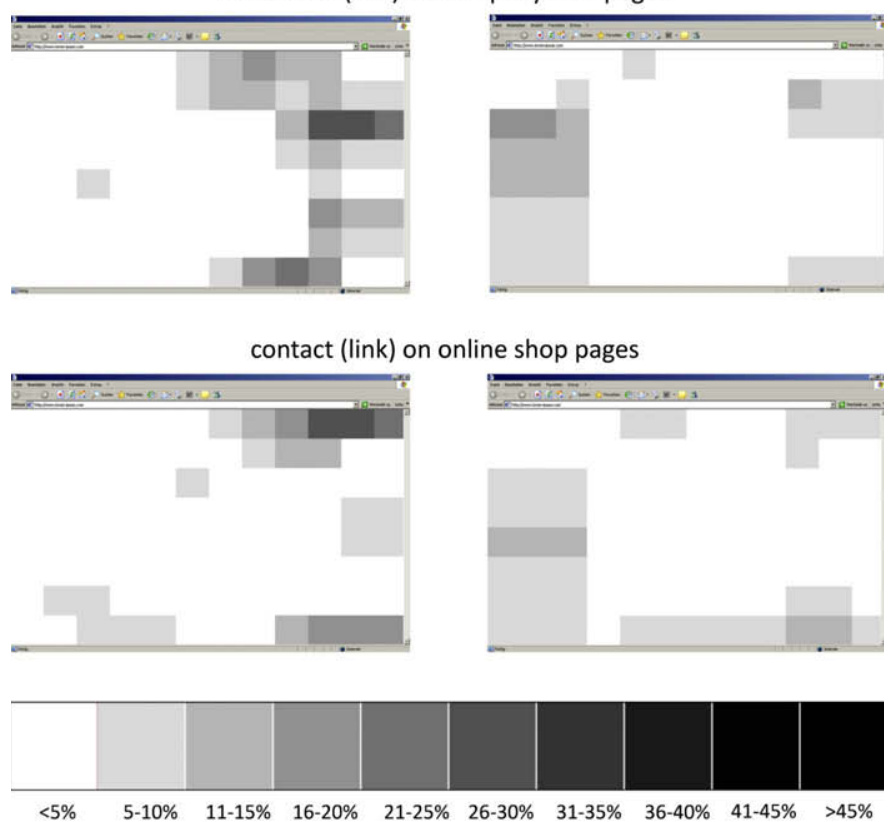

Fig. 9. Placements of web objects that did not correspond significantly between web design experts and laypeople. of web object locations. Even though self-ratings of computer and Internet abilities and frequencies of use differ significantly between genders their mental models revealed to be very congruent. This can be explained by the difference in self-assessment between women and men observed for example by Hargittai and Shafer (2006). Despite comparable online skills female users rated their skills lower than males. Probably, male and female participants of the present sample had the same online experience and expertise but exposed different self-assessed skills which explains the congruent mental models across all web objects.

The comparison between web design experts and laypeople showed a similar picture. Computer and web abilities are significantly higher in experts than laypeople. Except for three web objects ("external links" and "newsletter" of the company web page and the "contact" link of the online shop) their mental models correspond.

Results across all participants show that users generally agree about the locations of many, but not all, web objects. Most of them are expected to be at similar locations across the three different web page types. However, the location of "search field" differs between the web page types. The fact that the "about us" link was only distinctly placed on company web page indicates its importance on these respective web pages.

The patterns of the locations of the web objects differ to those found by Bernard (2001). The navigation area (called "internal website links" in Bernard's study) is the only web object that was placed similarly. Differences were found with "advertisement", "search field", and a little less markedly with the "back to homepage" link. A possible explanation for these differences could be that the design of both studies was very different. First - unlike the present work - in Bernard's study, participants were asked to place web objects on a typical web page without further specification. This could have led to a mixing-up of different website types, depending on the preference of the participants. However, in the present study the aforementioned web objects were placed at very similar locations across the different website types. This suggests that the difference of expected locations between Bernard's and this study are due to other reasons. Second, the present study was conducted online, where there is less control over the study procedure. Under these circumstances, one could assume that participants were not as motivated and did not take as much care in placing the web objects. Yet, taking into account Shaik and Lenz's (2006) similar findings concerning respective web objects, these differences could indeed be due to changes of the Internet appearance across time. Mental models for the examined web page types seem to be quite stable, as they were found regardless of the design differences, and the different populations of participants.

This pattern of expectations about web pages can now for example be applied to develop an index of typicality. In further studies, the relation between typicality index and usability measures of web pages should be examined. If web objects placed at typical locations are found faster and remembered better, perception of, satisfaction with and appeal of respective web pages may be improved.

There are several limitations of this study that have to be addressed. It is debatable if self-ratings of web design expertise are reliable enough as, e.g., Hargittai and Shafer (2006) have shown that men and women differ concerning their self-evaluation of Internet skills. A laboratory study examining professional web designers and/or at least more objective measures such as number of years of experience would help to clarify this point. Another important factor that was not controlled for was whether users understood the task as it was intended. It was not checked if people really designed the different web pages as they expect them to be or rather as they would like them to look. This also might have been possible to control better by letting participants explain at 


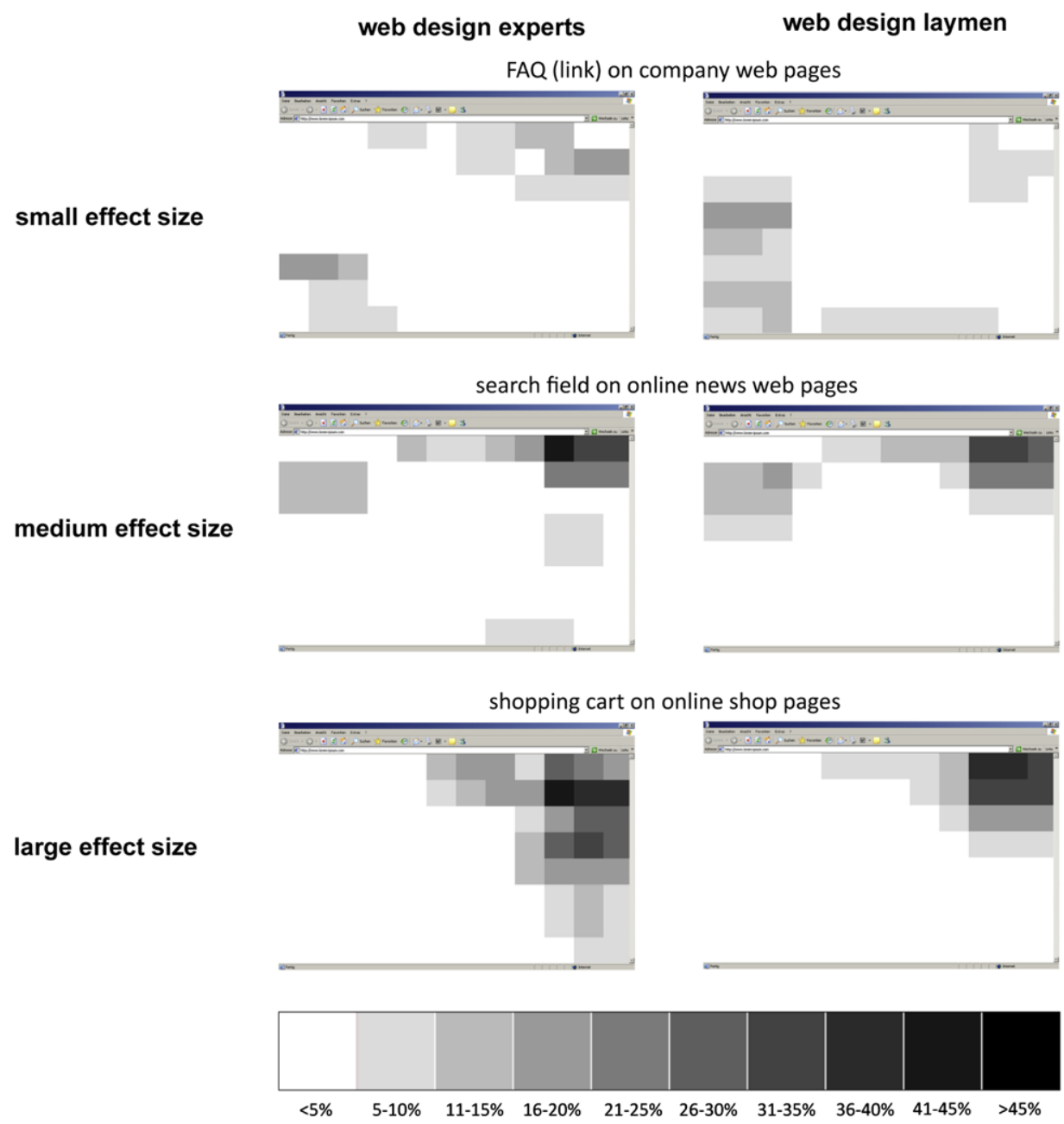

Fig. 10. Examples of web object placement representing one small, one medium, and one large effect size between experts and laypeople.

the conclusion what their task consisted of. Even though the sample was fairly large further studies are necessary including a broader population. The majority of the present sample was German speaking and between 15 and 30 years of age. Also, most participants were quite experienced web users. To examine how fast mental models evolve and how they develop a sample of very inexperienced web users should be included.

\section{Conclusion and future work}

People browsing the Internet seem to build up certain expectations for the location of common web objects on web pages. Regardless of the study environment, laboratory setting or online survey, a range of common web objects seems to be expected at certain locations. The outcome suggests also that Internet users build specific mental models of different web page types regarding certain web objects. Despite the freedom participants enjoyed with placing and resizing the web objects, a broad consensus of web object patterns was observed, suggesting that users have generated mental models through time that are quite stable. The expectations are quite congruent across gender and varying web design expertise. Using this knowledge appropriately could improve the perception and usability of websites. A couple of studies have already shown that applying mental models increase speed and orientation on web pages (Oulasvirta et al., 2005; Santa-Maria and Dyson, 2008). However, we do not suggest using the mental models, or users' expectations of web pages reported here as strict guidelines for web page design. Further studies should explore when web page design congruent to users' expectations is beneficial and when it should or may be broken. We do not know yet whether people prefer web pages that are consistent with their expectations or whether they prefer to be surprised by unexpected designs. Also, it may make sense to place some specific web objects at expected locations and others at unexpected. Future studies should measure under what circumstances users have fewer problems solving specific tasks, and are more satisfied with the interface.

\section{References}

Alexa - The Web Information Company, August 2008. Top sites by country. URL http://www.alexa.com/site/ds/top_500.

Apple Inc., August 2007. Apple human interface guidelines. URL http:// developer.apple.com/documentation/UserExperience/Conceptual/ AppleHIGuidelines/XHIGIntro/chapter_1_section_1.html.

Bargas-Avila, J., Oberholzer, G., Schmutz, P., de Vito, M., Opwis, K., 2007. Usable error message presentation in the World Wide Web: do not show errors right away. Interacting with Computers 19 (3), 330-341.

Bartlett, F., 1932. Remembering: A Study in Experimental and Social Psychology. Cambridge University Press, Cambridge.

Ben-Ari, M., Yeshno, T., 2006. Conceptual models of software artifacts. Interacting with Computers 18 (6), 1336-1350.

Bernard, M., 2001a. Developing schemas for the location of common web objects. In: Proceedings of the Human Factors and Ergonomics Society 45th Annual Meeting.

Bernard, M., 2001b. User expectations for the location of web objects. In: CHI Interactive Posters. ACM Press. 
Bernard, M., 2002. Examining user expectations for the location of common ecommerce web objects. URL http://www.surl.org/usabilitynews/41/ web_objectecom.asp.

Chevalier, A., Kicka, M., 2006. Web designers and web users: influence of the ergonomic quality of the web site on the information search. International Journal of Human Computer Studies 64 (10), 1031-1048.

Cohen, J., 1988. Statistical power analysis for the behavioral sciences. Lawrence Earlbaum Associates, Hillsdale, NJ.

Cooper, J., 2006. The digital divide: the special case of gender. Journal of Computer Assisted Learning 22, 320-334.

Cooper, J., Weaver, K., 2003. Gender and Computers: Understanding the Digital Divide. Lawrence Erlbaum Associates, Mahwah, NJ.

Craik, K., 1967. The nature of explanation. Cambridge University Press.

Denham, P., 1993. Nine-to fourteen-year-old children's conception of computers using drawings. Behaviour \& Information Technology 12 (6), 346-358.

Farris, J., Jones, K., Elgin, P., 2002. Users'schemata of hypermedia: what is so 'spatial' about a website? Interacting with Computers 14 (5), 487-502.

Fox, S., 2004. Older Americans and the internet. Pew Internet and American Life Project, Washington, DC

Fox, S., Madden, M., 2005. Generations online, vol. 5. Pew Internet and American Life Project, Washington, DC

Gentner, D., Stevens, A.L., 1983. Mental Models. Lawrence Erlbaum Associates, Hillsdale, New Jersey.

Green, A., 1994. Interacting cognitive subsystems: a framework for considering the relationship between performance and knowledge representation. Interacting with Computers 6 (1), 61-85.

Hargittai, E., Shafer, S., 2006. Differences in actual and perceived online skills: the role of gender. Social Science Quarterly 87 (2), 432-448.

Howard, P., Rainie, L., Jones, S., 2001. Days and nights on the Internet: the impact of a diffusing technology. American Behavioral Scientist 45 (3), 383.

Hsu, Y., 2006. The effects of metaphors on novice and expert learners' performance and mental-model development. Interacting with Computers 18 (4), 770-792.

IBM, August 2008. Design principles. URL http://www-01.ibm.com/software/ucd/ designconcepts/designbasics.html.

International Standards Organisation, 1998. 9241-11 Ergonomic requirements for office work with visual display terminals (VDT)s - Part 11 Guidance on usability. International Standards for Business, Government and Society.

Johnson-Laird, P., 1983. Mental Models. Harvard University Press, Cambridge

Kerr, S., 1990. Wayfinding in an electronic database: the relative importance of navigational cues vs. mental models. Information Processing and Management 26 (4), 511-523.

Koyani, S., 2006. Research-based web design \& usability guidelines. U.S. Department of Health and Human Services, Washington. URL http://www.usability.gov/ pdfs/guidelines.html.

Madden, M., 2006. Internet penetration and impact, vol. 26. Pew Internet and American Life Project Memo, Washington, DC.
May, M., 1996. Wörterbuch der Kognitionswissenschaften [Dicitionary of cognitive science]. Klett-Cotta, Stuttgart, Ch. Modell, mentales.

Mayhew, D., 1992. Principles and guidelines in software user interface design. Prentice Hall, Englewood Cliffs, NJ.

Minsky, M., 1975. The psychology of computer vision. McGraw-Hill, New York, Ch. A framework for representing knowledge, pp. 211-277.

Norman, D., 1983. Mental Models. Lawrence Erlbaum Associates, Hillsdale, New Jersey, Ch. Some observations on mental models, pp. 7-14.

Otter, M., Johnson, H., 2000. Lost in hyperspace: metrics and mental models. Interacting with Computers 13 (1), 1-40.

Oulasvirta, A., 2004. Task demands and memory in web interaction: a levels of processing approach. Interacting with Computers 16 (2), 217-241.

Oulasvirta, A., Kärkkäinen, L., Laarni, J., 2005. Expectations and memory in link search. Computers in Human Behavior 21 (5), 773-789.

Payne, S.J., 2007. Mental Models in Human-Computer Interaction. In: The HumanComputer Interaction Handbook: Fundamentals, Evolving Technologies, and Emerging Applications. Lawrence Erlbaum Assoc Inc., New York.

Pinkard, N., 2005. How the perceived masculinity and/or femininity of software applications influences students. Journal of Educational Computing Research 32 (1), 57-78.

Rouse, W., Morris, N., 1986. On looking into the black box: prospects and limits in the search for mental models. Psychological Bulletin 100 (3), 349-363.

Santa-Maria, L., Dyson, M.C., 2008. The effect of violating visual conventions of website on user performance and disorientation. How bad can it be? SIGDOC'08, 47-54.

Sears, A., Jacko, J. (Eds.), 2007. The Human-Computer Interaction Handbook: Fundamentals, Evolving Technologies, and Emerging Applications. Lawrence Erlbaum Associates Inc., New York.

Shaik, A., Lenz, K., 2006. Where's the search? Re-examining user expectations of web objects. URL <http://www.surl.org/usabilitynews/81/webobjects.asp>

Shneiderman, B., Plaisant, C., 2005. Guidelines principles and theories, forth ed. Designing the User Interface, vol. 2 Addison Wesley, Boston. pp. 74-76.

Spool, J.M., 2008. The wheres and whens of users' expectations. URL <http:/ www.uie.com/articles/user_expectations>.

Thatcher, A., Greyling, M., 1998. Mental models of the Internet. Internationa Journal of Industrial Ergonomics 22, 299-305.

Tognazzini, B., 1992. Tog on Interface. Addison-Wesley, Reading MA

Tuch, A., Bargas-Avila, J., Opwis, K., Wilhelm, F., 2009. Visual complexity of websites: effects on users' experience, physiology, performance, and memory. International Journal of Human-Computer Studies 67 (9), 703-715.

Weiss, J., 2006. Small tooltip library on top of prototype. Version 0.2 . URL <http:// blog.innerewut.de/files/tooltip/tooltip-v0.2.js>.

Wilson, K., Wallin, J., Reiser, C., 2003. Social stratification and the digital divide. Social Science Computer Review 21 (2), 133-143.

Zorn, W., 2007. Javascript: Dhtml api, drag \& drop for images and layers. Version 4.89. URL < http://www.walterzorn.com/dragdrop/dragdrop_e.htm>. 